Bucknell University

Bucknell Digital Commons

\title{
Validating the Client Focused Considering Work Model for People Living With HIV and Quantifying the Phases of Change of Commitment to Work
}

Liza M. Conyers

Penn State University, Imc11@psu.edu

K B. Boomer

Bucknell University, kmb031@bucknell.edu

Follow this and additional works at: https://digitalcommons.bucknell.edu/fac_journ

\section{Recommended Citation}

Conyers, Liza M. and Boomer, K B.. "Validating the Client Focused Considering Work Model for People Living With HIV and Quantifying the Phases of Change of Commitment to Work." Disability and Rehabilitation (2015).

This Article is brought to you for free and open access by the Faculty Scholarship at Bucknell Digital Commons. It has been accepted for inclusion in Faculty Journal Articles by an authorized administrator of Bucknell Digital Commons. For more information, please contact dcadmin@bucknell.edu. 


\section{Validating the client-focused considering work model for people living with HIV and quantifying phases of change of commitment to work}

\section{Liza M. Conyers \& K.B. Boomer}

To cite this article: Liza M. Conyers \& K.B. Boomer (2016): Validating the client-focused considering work model for people living with HIV and quantifying phases of change of commitment to work, Disability and Rehabilitation, DOI: 10.1080/09638288.2016.1180433

To link to this article: http://dx.doi.org/10.1080/09638288.2016.1180433

曲 Published online: 14 Sep 2016.

Submit your article to this journal $[\pi$

Џll Article views: 1

Q View related articles $\longleftarrow$

View Crossmark data ¿ 


\title{
Validating the client-focused considering work model for people living with HIV and quantifying phases of change of commitment to work
}

\author{
Liza M. Conyers ${ }^{\mathrm{a}}$ and K.B. Boomer \\ ${ }^{a}$ Department of Educational Psychology, Counseling, and Special Education, Penn State University, University Park, PA, USA; ${ }^{b}$ Department of \\ Mathematics, Bucknell University, Lewisburg, PA, USA
}

\begin{abstract}
The primary purpose of this study was to validate the client-focused considering work model and to gain a better understanding of the nature of the relationship among the four domains purported to influence the considering work process (medical, psychosocial, financial/legal and vocational). A second goal of the study was to quantify the relationship between these four domains and the phases of considering work (contemplation, preparation, action, resolution). Structural equation modeling was used to analyze data of 1702 diverse (43\% Black, 31\% White, 19\% Latino 7\% other) unemployed respondents who were recruited from AIDS Service Organizations (ASO) and networks across the United States to complete the National Working Positive Vocational Development and Employment Needs Survey (NWPC-VDENS). Overall the results of this study supported the validity of the client-focused considering work model and helped to provide a deeper level of understanding of the relationship among the domains of influence and their contribution to the level of commitment to the considering work process.
\end{abstract}

\section{ARTICLE HISTORY}

Received 8 June 2015 Revised 23 February 2016 Accepted 15 April 2016 Published online 26 August 2016

\section{KEYWORDS}

Client-focused considering work model; HIV; work

\section{> IMPLICATIONS FOR REHABILITATION}

- This model enables rehabilitation professionals to consider interventions for clients at different phases (contemplation, preparation, action) of considering work.

- Rehabilitation professionals are encouraged to provide prevocational services to engage people with HIV in the considering work process.

- When assisting PLWH within the considering work process, it is important to assess not only medical status but also psychosocial, financial and vocational concerns.

\section{Introduction}

As with people with psychiatric disabilities and/or other chronic illnesses, the medical breakthroughs that have occurred in HIV medicine have provided the potential for living longer and often healthier lives. However, many complications remain (e.g., unstable health trajectories, gaps in work history, stigma, financial disincentives, health disparities, poverty) with respect to making vocational decisions, whether they be considering work for the first time, contemplating return to work or assessing the ability to maintain employment and/or the impact of employment on health. Although prominent vocational and rehabilitation psychologists have called for greater attention to this population, as well as other marginalized groups and those living in poverty, [1-4] little research has focused on understanding and measuring the process of considering work for these populations.

Review of the HIV employment, career development, vocational psychology and rehabilitation literature reveals a sound body of research related to HIV that has explored a range of topics including vocational needs/experiences,[5-7] use of vocational rehabilitation services, $[8,9,10]$ and impact of employment interventions on vocational outcomes.[11,12] More recently a new area of research has begun to emerge examining the impact of employment and vocational services on medication adherence and/or public health outcomes.[13,14] However, only one study has examined the considering work process and the complex interaction of medical, psychosocial, financial/legal and vocational issues that can influence critical vocational decisions.[15]

Emerging research, which underscores the role that vocational services can play in helping to achieve the goals of the National HIV/AIDS Strategy (e.g., increased access to care and improved health outcomes associated with a reduction in HIV transmission) supports the need to apply career theories to research with this population and to better understand the valuable contributions that vocational and rehabilitation psychology can make to public health.[13] Research findings indicate that employment transitions in general are associated with changes in health-related lifestyle and that an upward employment trajectory is associated with no changes or healthy lifestyles, while a downward employment trajectory is associated with increased health-risk behaviors.[16,17] Research related to HIV-positive injection drug users illustrates this trajectory. In one study, Richardson et al. found an association between employment cessation and increased HIV-related risk exposure related to changes in drug use patterns and increased financial strain.[18] These findings suggest a potentially protective effect of employment against increased HIV-related risk. In another study with a similar population, Richardson et al. found that even among the most vulnerable injection drug users, those who reported regular, temporary or self-employment income were at 
significantly lower risk of death than those reporting no employment.[19] Additionally, Nachega et al. [14] conducted a meta-analysis of 28 studies involving 8743 people living with HIV (PLWH) and found that the odds ratio for the association between being employed and ART adherence was 1.27. Given the increased potential for PLWH to consider work and the significant personal, economic, social and public health consequences of unemployment and/or premature loss of employment, it is critical that HIV and rehabilitation researchers develop a better understanding of the individual barriers and motivators (such as health perception, social security benefits and perception of HIV stigma) that influence vocational decisions among PLWH. In 2005, Goldblum and Kohlenberg [20] developed a comprehensive model of vocational counseling for PLWH entitled, "Vocational Counseling for People with HIV: The Client-Focused Considering Work Model." This model identifies key domains that influence the vocational decisionmaking process, but this model has yet to be validated through empirical research.

\section{The client-focused considering work model}

The client-focused considering work model posits that there are four main domains of influence that typically motivate and/or inhibit vocational decision-making among PLWH: (a) medical, (b) psychosocial, (c) financial/legal and (d) vocational.[20] These domains were selected on the basis of commonly explored topics in vocational rehabilitation and career counseling as well as empirical research related to the pressures and barriers to employment among people with disability.[20] It is theorized that by taking into account these four domains, PLWH who are considering work increase their ability to make well-informed decisions that maximize individual outcomes and minimize the undesirable costs, even if the outcome should result in an active decision not to work.

A unique component of this model is that it not only identifies the four key domains that are theorized to motivate or limit vocational decision making, it also articulates clear phases of the decision-making process. Incorporating the stages of change theory [21] into their model, Goldblum and Kohlenberg [20] delineate four phases of considering work: (a) contemplation, (b) preparation, (c) action and (d) resolution. While the authors note that the process of considering work is nonlinear, they posit that it typically starts with a perceived pressure for change by the PLWH. This pressure may be influenced by changes in one's medical status (e.g., improved health), psychosocial (e.g., boredom), financial/legal (e.g., economic need; release from prison) and/or vocational (e.g., vocational identity).

Each phase of the considering work model highlights a sequence of different decisions and related activities that a person would need to process in order to effectively evaluate the benefits and risks of making a change. The decisions considered in each of these phases are influenced by the four key domains of influence. Within the contemplation phase, the key question to address is: Whether or not any change is feasible? This requires an evaluation of the benefits and risks associated with each of the four domains of influence. During the preparation phase, the key question is What change is best? Within the preparation phase, individuals explore and set vocational goals and develop plans for meeting those goals. This phase can include activities such as identifying sources of training, participating in workshops or seeking career counseling, all of which can be influenced by factors within the four domains of influence. As one moves into the action phase of considering work, the main question to address is: How to achieve the stated goals? The main tasks associated with this phase are the implementation and refinement of vocational goals and evaluating the impact of these goals on the four domains of influence. Each of these phases of considering work reflect incremental degrees of commitment to engaging in the considering work process. Resolution is the fourth phase of the Client-Focused Considering Work Model and the main question to assess in this phase is: Has pressure to change resolved? The main activity associated with this task is to either adapt to new work activities or resolve pressure through alternative means. Unlike the traditional Stages of Change Theory,[21] the client-centered considering work model does not include an underlying value assumption on employment status that is commonly associated with health-related problems typically addressed with the stages of change theory (e.g., alcoholism, smoking). Since the client-focused considering work model does not view the status of PLWH being unemployed as inherently problematic, there is no precontemplation phase within this model in which the awareness of a problem must be brought to consciousness. As such there is also no concept of relapse within the client-focused considering work model, although PLWH may reconsider their decisions and move back and forth across the phases of considering work. Given the high level of anxiety that can be generated in this process and the medical, psychosocial, financial and vocational consequences, it is critical that individuals have the flexibility to reconsider their goals. Allowing for the possibility of reconsideration can help $\mathrm{PLWH}$ be more open to considering changes associated with moving forward in the considering work process without fearing that they will be forced to accept negative outcomes.[22] Figure 1 depicts the overall process from pressure for life change (domains of influence) to the phases of considering work and resolution. This figure also illustrates the idea that as individuals experience more or less positive outcomes for each of the domains of influence, they are more or less likely to be in different phases of considering work.

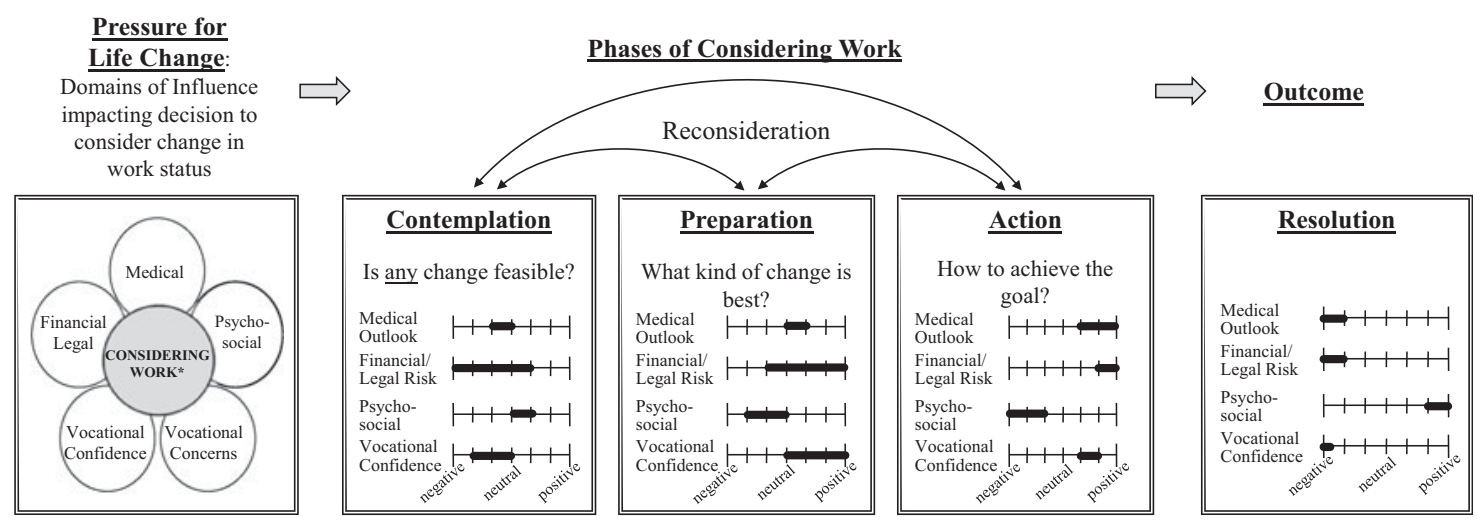

Figure 1. Client-focused considering work model. 
Although the client-focused considering work model has tremendous face validity, shares similarities with several other HIV and employment models $[7,22]$ and provides $\mathrm{PLWH}$, rehabilitation and career counselors with a systemic approach to conceptualize and work through the vocational decision-making process, it has never been validated empirically. Given the potential utility of this model for expanding understanding of the vocational decisionmaking process that could have important implications for the development of vocational services and policies regarding employment, there is a critical need to better understand the degree to which the main components of the model are supported empirically. Furthermore, it is important to expand upon the proposed model by investigating the nature of the interactions among the proposed domains. With this in mind, this study has two main purposes, each with two related research questions. With the goal of validating the client-focused considering work model, we ask (a) what are the individual barriers and facilitators of employment associated with the domains of influence as proposed in the client-focused considering work model? And (b) what is the relationship among the proposed domains? Second, with the objective to quantify the relationship between the domains and the phases of considering work, this study explores the following: (c) what are the relationships among domains that are associated with increased shift from contemplation into action in the considering work process? And (d) how do the four domains impact the probability of being in different phases of considering work?

\section{Methods}

\section{Participants and instrument}

This study used structural equation modeling to analyze data of 1702 unemployed respondents who were recruited from AIDS Service Organizations (ASO) and networks across the United States to complete the National Working Positive Vocational Development and Employment Needs Survey (NWPC-VDES).[23] This survey was the first to explore the vocational needs of PLWH in the United States and included four major sections consisting of demographic variables, knowledge and use of vocational resources, questions related to employment status and several healthrelated subscales from the HIV Medical Outcomes Study [MOS-HIV, 24]. Item development was designed to identify and assess barriers and facilitators to employment and vocational development and was based upon extensive literature review, integrating results from focus groups among diverse populations impacted by HIV (African-American and Latina women, men who have sex with men, heterosexual men) in different regions of the United States and expert panel review. The NWPC-VDENS took about 30-45 min to complete and was available in paper and the Internet formats in both English and Spanish.

Volunteer participants represented diverse racial $43 \%$ Black, $31 \%$ White, $19 \%$ Latino, $7 \%$ other), gender (64\% male, 35\% female, $1 \%$ transgender) and sexual orientation (53\% heterosexual, 38\% gay, $9 \%$ bisexual) backgrounds. The mean age of the sample was 47. The majority of respondents were from low-income backgrounds (70\% receive less than $\$ 15,000$ per year) and many had experienced significant barriers to employment such as homelessness (59\%), drug abuse (53\%) and incarceration (38\%). About a quarter reported never using the Internet or email.

Using a scale designed to assess individual phases of considering work, respondents were classified into the four phases of considering work (contemplation, preparation, action and resolution), creating a four-level nominal endogenous variable, based on responses to six questions (Table 1). Responses were coded using
Table 1. Items used to classify phase of work.

\begin{tabular}{ll}
\hline Num. & \multicolumn{1}{c}{ Items } \\
\hline 1. & I have carefully considered the impact of working on all parts of my life \\
2. & Getting a job is not a priority for me right now \\
3. & I am determined to find a job despite the obstacles \\
4. & I am working toward getting a job instead of just thinking about it \\
5. & Having a job might be a positive change in my life \\
6. & I am ready for work today \\
\hline
\end{tabular}

expert knowledge based on theories of stages of change. Characteristics of each phase, with the percent of the sample represented, are presented later.

Those in the contemplation phase (35\%) had carefully considered the impact of working but felt getting a job was not a priority at the moment. Those in the preparation phase $(24 \%)$ generally had carefully considered the impact of working, although may or may not have felt getting a job was a priority. However, those in this latter group indicated either a determination to find a job despite the obstacles or were currently working towards getting a job instead of just thinking about it. Those in the action phase (26\%) were determined to find a job despite the obstacles, were working toward getting a job and felt getting a job would be a positive change. The resolutions phase (15\%) was characterized by no more than one positive statement about job seeking. This included individuals who indicated they were not considering work as well as individuals who had decided not to pursue finding employment.

\section{Data analysis}

Statistical analyses were conducted using Mplus v7 (Los Angeles, CA).[25] A factor analysis was conducted on the NWPC-VDENS to identify items that significantly loaded onto each of the domains of influence. Items with factor loadings of $\lambda=0.4$ or greater were retained. Further, items measured on five-point Likert scales, or fewer categories, were treated as ordinal variables, to avoid biases with the estimates associated with treating such variables as continuous. Structural equation modeling was used to better understand the relationship among the domains of influence. An initial confirmatory factor analysis, representing the measurement aspect of the statistical model, was combined in the structural model with least-squares linear regressions to explore the associations among the five exogenous latent variables (medical, psychosocial, financial/legal and two vocational domains) and a multinomial probit analysis to assess the effect of the latent domains on the endogenous (i.e., outcome) variable of phases of considering work (nominal). Standardized least-squares regression coefficients and probit regression coefficients are reported below (both reported as $b$ ); the latter are used to estimate the probability (prob) of being in each phase of considering work given values of the domain latent factors. A robust weighted least-squares estimator (WLSMV) in Mplus $[26,27]$ was used to retain the ordinal nature of the variables. Because the analysis included binary, ordinal and continuous items, multivariate normality could not be assumed. Consequently, bootstrap resampling (1000 iterations) was used to obtain 95\% confidence intervals $(\mathrm{Cl})$ for standardized path coefficients within the structural equation model. Pairwise deletion was used within Mplus to respond to missing data, resulting in 1702 complete cases in the final analysis.

\section{Results}

Overall, the results of this study supported the validity of the client-focused considering work model and helped to provide a 
deeper level of understanding of the relationship among the domains of influence and their contribution to the level of commitment to the considering work process. The results are reported below by each of the research questions.

\section{Factors associated with the domains of influence proposed in the client-focused considering work model}

A factor analysis was conducted to identify items that significantly loaded onto each of the proposed domains of influence. There was a factor to represent each of the proposed domains (medical, psychosocial, financial/legal and vocational); however, the vocational domain had two subdomains, vocational confidence and vocational concerns, rather than holding together as one broad vocational domain. Each of these factors is defined in Table 2.

\section{The relationship among the four considering work domains}

The final structural equation model is presented in Figure 2 and all factor loadings were significant $(p<0.001)$. The fit of the final structural equation model was good (root mean square error of approximation $=0.046$, with $90 \%$ upper bound of 0.05 , comparative fit index $=0.95$, Tucker-Lewis index $=0.94$ ).

Each of the latent domains (medical, psychosocial, financial/legal, vocational confidence and vocational concerns) was scaled so that the mean is zero; the use of standardized leastsquares regression coefficients allows direct comparison of the relative effects among the domains. Vocational concerns have a direct negative effect on vocational confidence $(b=-0.16,(-0.24$, $-0.09))$. Together, vocational concerns $(b=-0.31,(-0.37,-0.26))$ and vocational confidence $(b=0.49,(0.44,0.55))$ have direct effects on the psychosocial domain. The psychosocial domain has a direct negative effect $(b=-0.81,(-1.13,-0.49))$ on the financial/legal domain and a direct positive effect $(b=0.88,(0.83,0.92))$ on the medical domain. The medical domain has a direct positive effect $(b=0.63,(0.30,0.95))$ on the financial/legal domain.

\section{The relationship among domains those are associated with increased shift from contemplation into action in the considering work process}

Standardized probit regression coefficients $(b)$ are reported below, along with the $95 \%$ bootstrapped confidence intervals. Thus, we can compare the relative effects of the four domains on the phases of considering work with the estimated coefficients. Probit coefficients are units of probability of being in one category of a nominal variable (e.g., action) measured in terms of changes in standard deviations of the predictor variable (e.g., medical domain) from its mean. Positive coefficients indicate further along the "considering work" continuum, moving from resolution toward action.

Table 2. Domain factor analysis.

Domain description and Items

Estimate (SE)

Medical: Higher scores indicate better health perceptions and less health distress

MOS General Health Perception

MOS Health Distress scale (higher values indicate lower distress)

$0.70(0.019)$

Psychosocial: Higher scores indicate less stigma and better overall mental health

Sometimes I feel worthless because I am HIV positive $(1$ = strongly agree, . ., 5 = strongly disagree $) \quad 0.58$ (0.024)

Self-esteem $(1=$ low, $\ldots, 7=$ high $)$

MOS Cognitive Functioning Scale

MOS Mental Health Scale

Financial/Legal: Higher scores indicate less trust in social security and greater financial risk

I currently receive social security benefits $(0=$ yes, $1=$ no)

I currently have health insurance $(0=$ yes, $1=$ no)

I trust social security $(0=$ yes, $1=$ no)

I have had mostly positive experiences with social security $(0=$ agree, $1=$ disagree $)$

Vocational confidence: Higher scores indicate greater confidence in seeking and holding a job

How confident are you in your job seeking skills? $(1=$ low, . ., $7=$ high $)$

How confident are you that you could hold onto a job once you had it? $(1=$ low, $\ldots, 7=$ high $)$

$0.66(0.020)$

$0.66(0.020)$

$0.74(0.017)$

How confident are you that you could ask for job accommodations? $(1=$ low $, \ldots, 7=$ high $)$

Vocational concerns: Higher scores indicated more concerns associated with holding a job

Concerned about limited sick leave $(0=$ no, $1=$ yes $)$

Concerned about long hours related to a job $(0=$ no, $1=$ yes $)$

Concerned about keeping medical appointments $(0=$ no, $1=$ yes $)$

Concerned about physical duties $(0=$ no, $1=$ yes $)$

Concerned about limited break time $(0=$ no, $1=$ yes $)$

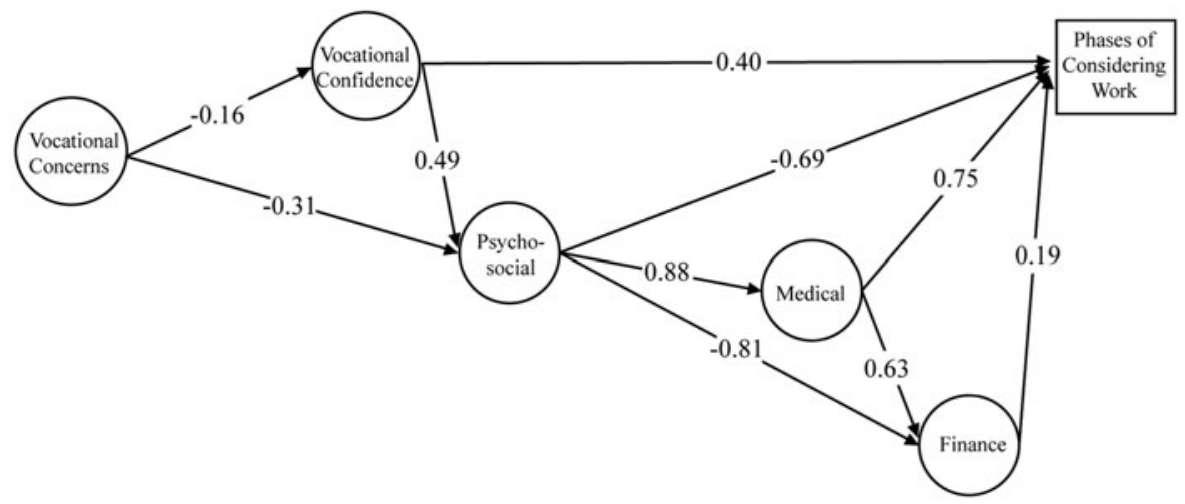

Figure 2. Final structural equation model showing the effect of the domains on the phases of considering work. 
The medical domain has the greatest positive direct effect $(b=0.75,(0.39,1.12))$ on the phases of work, followed by vocational confidence $(b=0.40,(0.32,0.48))$ and the financial/legal domain $(b=0.19,(0.09,0.30))$. Greater confidence, better health and greater financial risk are each associated with higher phases of considering work.

The psychosocial domain has a negative direct effect $(b=-0.69,(-1.07,-0.32))$ on considering work. Further, the psychosocial domain has a significant positive indirect effect on the phases of considering work through the medical domain $(b=0.66$, $(0.32,0.87))$ and a significant negative indirect effect on the phases of considering work through the financial/legal domain $(b=-0.16$, $(-0.18,-0.06))$. However, when the model only includes the psychosocial domain, it has a positive direct effect $(b=0.13,(0.06$, $0.20)$ ) on considering work. This suggests the possibility of mediation between the psychosocial domain and the medical and financial domains.[28]

\section{The impact of the four domains on the probability of being in different phases of considering work}

As noted in Figure 3, within the medical domain, the probability of being in the resolution phase is highest $(p r o b=0.94)$ among those with a poor health perception. This probability decreases to 0.1 at the mean medical factor score, when the probability of being in the action phase sharply increases. Individuals with the highest health perceptions scores have over a $97 \%$ chance of being in the
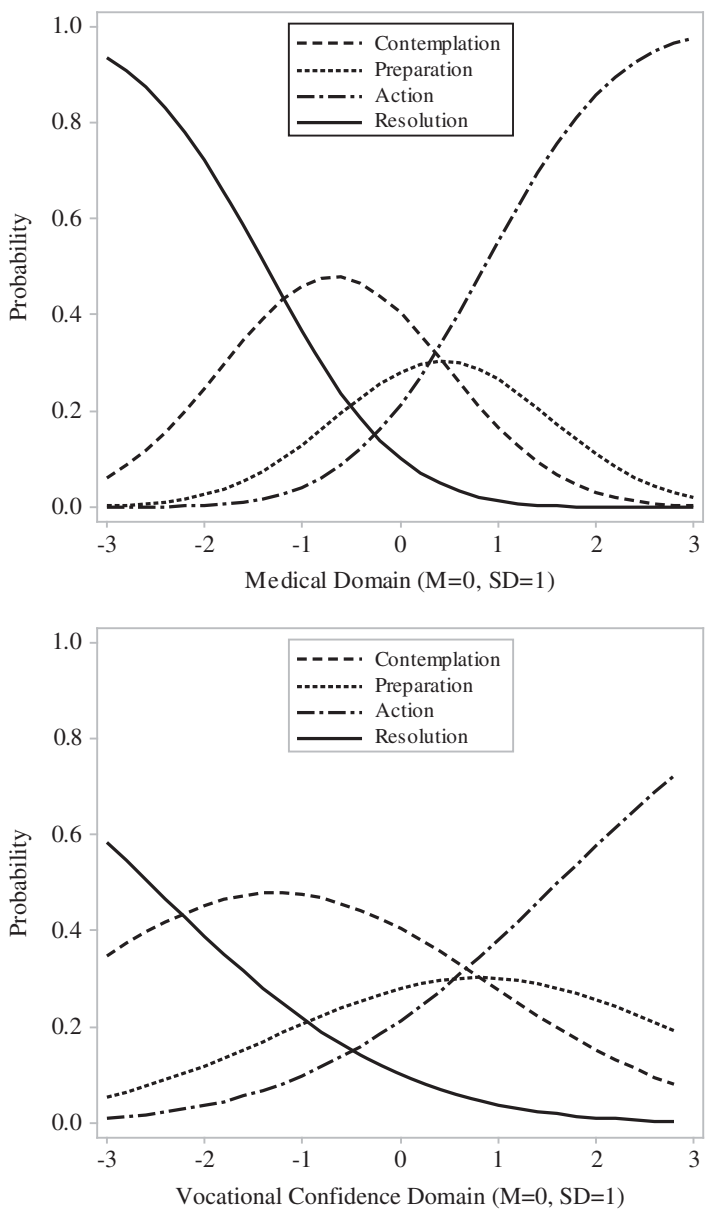

action phase. Individuals are most likely to be in the contemplative phase for medical domain scores one standard deviation below the mean. The intersection of the contemplation phase, preparation phase and action phase curves at approximately 0.5 SD above the mean suggests this is a transition point, with the potential to shift among the phases.

With respect to the financial/legal domain (Figure 3), individuals are most likely to be in the contemplation phase, although this probability decreases as the perception of financial risk increases. The transition point at approximate 1.5 SD above the mean can shift some individuals from the contemplation phase into the action phase.

As noted in Figure 3, individuals with the least confidence in their abilities to obtain or maintain a job are most likely to be resolved not to work or in the contemplation phase. The probability of being in the resolution phase drops steeply as one's confidence increases. A transition point exists at one SD above the mean vocational confidence domain score, at which the probability of action increases, and the probability of preparation exceeds the probability of contemplation.

Although we ran probability analyses for each of the four domains both independently and simultaneously with the other domains, the psychosocial domain was the only domain where there were differences in the patterns of probability outcomes across the phases of considering work when run simultaneously with the other domains. To get a better understanding of the unique contribution of the psychosocial factors, Figure 3 shows
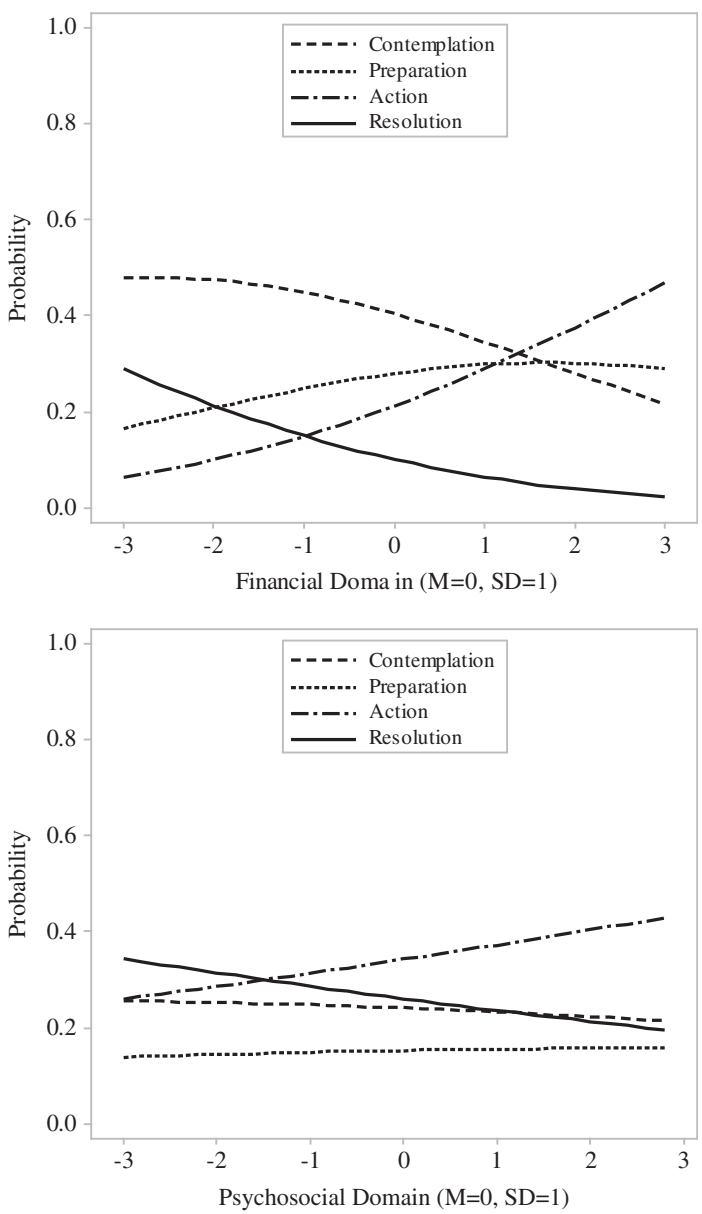

Figure 3. Probability plots demonstrating the probability of being in each phase of considering work within each domain of influence: medical, financial/legal, vocational, and psychosocial. 
the probability curves in a model considering the effect of psychosocial aspects on the phases of considering work, ignoring the impact of the medical, financial/legal, and vocational domains. These findings indicate that as mental health improves and sigma decreases, the probability that one is in the action phase increases, while the probability one is in the resolution phase decreases. The key transition point is about 1.75 SD below the mean.

\section{Discussion}

The primary purpose of this study was to empirically validate the client-focused considering work model for People with HIV.[20] Overall, this study provided support for the validity of this model with factor loadings on each of the model's four purported primary domains of influence (medical, psychosocial, financial/legal, vocational) that impact the level of commitment (contemplation, preparation, action, resolution) to considering a change in employment status. The study findings revealed that the vocational domain had two subdomains, vocational confidence and vocational concerns, rather than one broad vocational domain. As discussed in greater detail below, this is consistent with career theories that distinguish between internal (e.g., self-confidence) and external (e.g., limited break time) vocational barriers. The secondary purpose of the study was to better understand the relationship among the domains of influence and to quantify how changes within each of the domains impact the probability of being in different phases of considering work among a sample of PLWH. Study findings indicate that the medical domain had the greatest positive effect on increasing one's commitment to considering work but that the other psychosocial, financial/legal and vocational domains also play an important roles that are often inter-related. In response to the two primary research questions, this study makes several contributions to career theory and vocational rehabilitation literature. First, this study developed a statistical model to help both define and examine the relationship among the domains of influence proposed in the client focused considering work model. Second, this study describes a mechanism to evaluate the relative importance of the considering work domains and the probability of transitioning from one phase of considering work to another as changes occur within and among the domains of influence. Overall, the findings provide empirical support for the key components posited in the client-focused considering work model. This discussion will elaborate on these findings in greater depth and conclude with implications for practice and future research.

\section{Validation of the client-focused considering work model}

In contrast to the four domains proposed in the client-focused considering work model, this study identified five factors. Each of these factors was consistent with the proposed domains in the model; however, in this study, the vocational domain was partitioned into two separate subfactors which we defined as vocational concerns and vocational confidence. The items within the vocational confidence factor each made a similar level of contribution (ranging from $\lambda=0.76$ to 0.83 ) with confidence in the ability to ask for a job accommodation carrying the greatest weight $(\lambda=0.83)$. Among the vocational concerns items, the impact of specific concerns ranged from $\lambda=0.76$ (limited sick leave) to $\lambda=0.94$ (limited break time). These findings are consistent with the description of the vocational domain provided in the clientfocused considering work model and with prominent career theories. Within their description of the vocational domain, Goldblum and Kohlenberg [20] indicate that vocational barriers may be internal (e.g., lack of confidence, lack of skills, poor vocational attitudes) or external (e.g., poor support and or labor market, limited resources, discrimination). As one of the most prominent career theories, social cognitive career theory also makes a clear distinction between the role of self-efficacy (confidence in ability to perform specific career-related tasks) and work barriers, which are often reflected and measured by the level of concern a person has about varied factors impacting their ability to work.[29] Previous research has also found that lack of flexible schedules (e.g., time off to see doctor, limited breaks) is consistently among the most highly rated barriers to work/work-related concerns for PLWH.[30]

Examination of the relationship among the domains of influence supports the basic premise of the client-focused considering work model that these domains are interrelated. Review of the structural equation model highlights both direct and indirect paths among the five domains and helps deepen our understanding of the nature of the relationship among the domains. The finding that vocational concerns have a direct negative impact on vocational confidence is consistent with previous research related to self-efficacy where self-confidence is believed to develop through positive personal and environmental interactions.[31] Ironically, research also indicates that those who perceive more difficulties in seeking employment may be less likely to use vocational rehabilitation services that are specifically designed to assist individuals with disabilities overcome barriers and provide job accommodations.[8,32] These findings underscore the need for prevocational interventions to reduce vocational concerns, which may increase vocational confidence and help facilitate a more advanced phase of commitment to considering work.

The finding that, taken together, vocational concerns and vocational confidence have a direct effect on the psychosocial domain, underscores the important role that vocational development plays in contributing to positive outcomes such as improved selfesteem, better mental health and reduced stigma. The unique role that employment can play in reducing stigma in the lives of PLWH highlights the importance of career and vocational rehabilitation services for this population, not just for the specific goal of obtaining employment but for the potential for these services to improve other key outcomes such as quality of life and improved mental health. Employment services can not only distract a person from a "sick role" to a productive engagement in society, but it also provides social stature and the prospect of increased economic independence.[33] These are all critical factors in reducing the negative impact of disability and facilitating improved quality of life.

It is not surprising that less stigma and better mental health from the psychosocial domain is associated with lesser financial risk and trust in social security and having better health perceptions and lower levels of health distress. These findings are consistent with research related to the role that less financial strain and stigma can have on positive mental health outcomes. The finding that the medical domain had a positive direct impact on the financial/legal domain most likely reflects the likelihood that those who have higher levels of general health perception and lower health distress are less likely to be in need of social security or to have used these services to develop negative attitudes or lack of trust in these services. More research may be needed in this area to better understand the degree to which individuals with health conditions trust that social security would be available as a safety net, if needed.

Prior research provides strong support for the impact that HIV stigma can have on lack of engagement in care.[34] Individuals with higher self-esteem, less HIV stigma and better mental health and cognitive functioning have improved general health 
perceptions and reduced health distress. This suggests that more interventions related to reducing HIV stigma could play an important role in reducing health distress. Reduced stigma has also been associated with increased participation in vocational services and access to medical care.[13] Interventions to reduce HIV stigma are critical to improving public health outcomes associated with HIV and support the need for vocational services to be integrated into the interdisciplinary approach to responding to this epidemic

\section{Relative importance of the considering work domains}

Although the client-focused considering work model provides a framework for understanding the process of career engagement for PLWH, it does not specify the expected contribution of each of the domains of influence on the progression of change from contemplation to action. Gaining a better understanding of these processes can help to expand career and vocational rehabilitation counseling research as it relates to the unique needs and challenges of providing vocational services to PLWH. The world health organization (WHO) commission on social determinants of health noted that employment can provide "financial security, social status, personal development, social relations, self-esteem, and protection from physical and psychosocial hazards.",[35, p.72] A burgeoning body of research also supports key benefits of employment in terms of better physical health outcomes [22,36-38] as well as mental health outcomes such as reduced depression, anxiety and stress and increased coping and self-care $[36,38-40]$ and quality of life.[41,42] Since there is variation in the level and extent of both the barriers to and benefits of employment across studies, there is a critical need to better understand the considering work process to contribute to research studies examining the relationship between employment and health outcomes.[43] While it is widely recognized that people with chronic illness and disability, including those with HIV, often want to work, there is a major discrepancy between desire to work and actual rates of employment. This study's findings help to shed some light on the relative importance of each of the domains, the probability of transitioning to different phases of work as changes occur within each domain of influence, and the need to take all factors into consideration to better understand and explore the profound challenges that many PLWH face when engaging in the process of considering work.

The results of this study indicate that the medical domain has the most significant effect $(b=0.75)$ when considering which factors are most influential on the shift from contemplation into action. This suggests that with improved health perception and reduced health distress, participants are increasingly likely to shift from low levels of commitment to considering work (e.g., contemplation) to higher levels of commitment (e.g., action). This is consistent with existing public policies that place a narrow emphasis on relying on medical outcomes (e.g., CD4 counts, number of opportunistic infections, functional limitations) to determine eligibility for services such as social security disability and vocational rehabilitation. Importantly, participants with average levels of health distress and health perceptions were most likely to transition from other phases of considering work into action, which indicates that average health can increase commitment to considering work, prior to achieving optimal health outcomes. This finding suggests that there is some degree of variation in consideration of work across a range of health perceptions (average to optimal), and underscores the importance of looking beyond medical outcomes alone to better understand additional factors involved in the considering work process.
This study found that psychosocial factors also have a large effect $(b=-0.69)$ on transitioning between phases of considering work, albeit negative. Unfortunately, many public policy standards do not fully take into consideration the impact that psychosocial factors can play in the ability to engage in vocational services and employment. For example, psychosocial factors are often not considered in HIV disability determination and may not be fully considered for assessment of vocational rehabilitation eligibility. Over the past several years, services for PLWH have seen a decrease in funding for broader social services with an increasingly narrow focus on medical case management alone. Although these medical services are critical, it is essential that other factors also be taken into consideration when working to improve outcomes as research indicates that only about $40 \%$ of PLWH are engaged in care and that important psychosocial factors such as HIV stigma and poor mental health pose significant barriers to care.[44] The current study found that the impact of psychosocial factors appears to be more complex and more highly influenced by interactions with the other domains. However, when considering the unique contribution of psychosocial factors, it is important to note the impact of reduced stigma and increased mental health on the incremental levels of commitment to considering work. The more that stigma was reduced and mental health improved, the greater the likelihood of being in the action phase of considering work.

Another important finding from this study is the direct impact $(b=0.40)$ that increased vocational confidence has on increasing commitment to work. Prominent career development theories such as social cognitive career theory emphasize the critical role of self-efficacy in the vocational development process.[29] Our findings reveal that those with the least amount of confidence in their ability to seek work, request reasonable accommodations and/or maintain employment once hired were most likely to be in the resolved phase of considering work (not considering any change) or in the contemplation phases. Unfortunately, research indicates that many PLWH are not aware of the resources that can help increase vocational confidence [13] and may therefore prematurely foreclose engaging further in the considering work process. Receipt of quality career and/or vocational rehabilitation services has been associated with improved self-efficacy. These services would need to include increasing client awareness of the Americans with Disabilities Act as research also indicates that many PLWH are not aware of the right to receive a reasonable accommodation and may not know how to manage disclosure (or nondisclosure) of their HIV status when applying for work.[30]

Study findings also suggest that the financial/legal domain has a direct impact on engagement in considering work, albeit less than the other domains $(b=0.19)$. More than other domains, contemplation remains the most likely phase of considering work regardless of the level of change within the financial/legal domain. This finding underscores the powerful role that basic economic factors play in the high level of ambivalence that many PLWH have about considering work. Many of these individuals may be interested in working, however, in some cases, working without access to health insurance or adequate income may threaten their health and economic survival. For example, participants at the low end of financial risk may have more financial security associated with greater likelihood of receipt of social security benefits. They may have some interest in work but remain in the contemplation phase given the potential risk of losing benefits. As financial risk begins to increase, as noted at 1 SD below the mean, contemplation starts to decrease and preparation and action start to increase. At the mean, participants are still most likely to be in the contemplation phase $(p r o b=0.40)$, followed by preparation $(p r o b=0.28)$ and action $(p r o b=0.21)$. However, at $1 \mathrm{SD}$ above the 
mean, participants start to transition into the action phase of considering work, suggesting that once financial risk hits a critical point, transition into action is necessary, possibly to meet basic survival needs. When we consider the findings from the financial/ legal domain in conjunction with the medical domain, we can see how individuals may be compelled to work despite their health status, even if the additional stress of work would not lead to better HIV health and prevention outcomes. Given the potential for negative financial outcomes that can occur with transition to work for those who receive social security benefits or other disabilityrelated health insurance or housing subsidies, it is critical that evaluation of vocational services for this population include more than whether or not the person is employed for 90 days. Other health, prevention, and financial outcomes also need to be taken into consideration when evaluating the benefits of work. Similar to the research that demonstrates lack of awareness of career and vocational rehabilitation resources among $\mathrm{PLWH}$, research also indicates that many PLWH are not aware of the key financial resources such as Social Security work incentives and benefits counseling that could facilitate pathways to employment and economic empowerment.

\section{Implications for practice and future research}

This study helps us to better understand the relationship between interest in work among PLWH and actually taking steps to find work. The results underscore the importance of assessing each of the considering work domains individually, to help to better understand the factors that may pose the greatest challenge for individual participants to pursue employment. The ability to break the complex considering work process into discrete areas of assessment can help guide counselors to evaluate the barriers and facilitators of employment in each of the domains to help inform the selection of targeted resources and interventions for the specific domain or domains that pose the greatest barrier to considering employment. The finding that each of these domains is interrelated reveals that it is important to complete a comprehensive assessment rather than considering any one domain in isolation. Since the domains are interrelated, it is also likely that multimodal approaches to career and vocational rehabilitation interventions would be most effective for this population. This multimodal approach suggests that intervention on one of the domains may also impact the other domains of influence and that ongoing assessment is needed across all areas over time.

HIV and employment research is a relatively new area of focus and, as such, much of the research in this area is in a fairly exploratory state. One of the limitations of this study is the lack of available instruments that meet rigorous psychometric standards. The NWPC-VDENS instrument used for this study was the first instrument developed to conduct a nationwide vocational needs assessment for PLWH. Although this instrument was developed based upon expert panel review, a comprehensive literature search and results from focus groups in different areas of the country, no studies have been conducted to assess its psychometric properties. Factor loadings of items onto each of the domains measured herein (Table 2) indicates consistent factors, which provides some empirical support for the use of this instrument. Although this paper demonstrates conceptual validity for the client-focused considering work model, more research is needed to develop and validate measures that can better assess and group individuals into different phases of considering work. This type of instrument is needed to identify the most appropriate intervention to support individuals who may be at different phases of considering work and to conduct future research to better understand the interrelationship among factors associated with successful transitions to work. Another limitation of this study is that the data collection took place during 2008 through 2009 on a volunteer sample that could impact sample bias. Given the ongoing medical advancements in HIV medicine as well as changes in labor market demands noted over the past six years, ongoing research in this area is needed to remain current. Along with these advancements in HIV care, there is an emerging emphasis on the role of vocational services and employment as social determinants of health as noted in the revised US National HIV/AIDS Strategy [45] and in the International Labor Organization's Recommendation 200 calling for national policies and programs on HIV and employment that take specific measures to promote decent work, sustainable enterprises, and income generating strategies among PLWH.[46] Finally, the current study is based upon a cross-sectional design. Given the proposition within the client-focused considering work model that the process is nonlinear and that individuals may move back and forth among the phases of considering work, it would be helpful to conduct longitudinal research in this area to better assess phases of change over time. With respect to future research, the integration of intervention research methods in this line of inquiry is needed to better evaluate the degree to which targeted interventions are successful in addressing identified barriers and helping individuals make a successful transition to employment. Given the potential role of career and vocational rehabilitation interventions to lead to reduced HIV stigma and positive health and prevention outcomes,[11] we recommend the use of multiple methods to evaluate career and vocational rehabilitation services that go beyond job placement alone and include key HIV health and prevention outcomes (e.g., undetectable viral load, increased CD4 count, increased engagement in care, reduced HIV stigma) associated with the updated goals of the National HIV/AIDS Strategy.[45]

\section{Acknowledgements}

The authors would like to thank the participants for taking the time to complete the survey. The authors would like to acknowledge the National Working Positive Coalition (workingpositive.net), a coalition of individuals living with HIV, service providers, researchers, and advocates who are committed to improving the financial and personal well-being of individuals living with HIV/ AIDS.

\section{Disclosure statement}

The authors report no conflicts of interest.

\section{Funding information}

This study was possible due to funding from the National Institute on Disability and Rehabilitation Research (NIDRR) Mary Switzer Fellowship and the AIDS Institute - New York State Department of Health.

\section{References}

[1] Blustein DL, Kenna AC, Gill N, et al. The psychology of working: a new framework for counseling practice and public policy. Career Dev Q. 2008;56:294-308.

[2] Blustein DL, McWhirter EH, Perry JC. An emancipatory communitarian approach to vocational development theory, research, and practice. Couns Psychol. 2005;33:141. 
[3] Werth JL, Borges NJ, McNally CJ, et al. Integrating health and vocational psychology HIV and employment. Couns Psychol. 2008;36:8-15.

[4] Werth JL, Borges NJ, McNally CJ, et al. The intersections of work, health, diversity, and social justice helping people living with HIV disease. Couns Psychol. 2008;36:16-41.

[5] Conyers LM, Datti P. The unmet vocational rehabilitation needs of women with HIV/AIDS. Work. 2008;31:277-290.

[6] Hergenrather KC, Rhodes SD, Clark G. Windows to work: exploring employment-seeking behaviors of persons with HIV/AIDS through Photovoice. AIDS Educ Prev. 2006;18:243-258.

[7] Maguire CP, McNally CJ, Britton PJ, et al. Challenges of work: voices of persons with HIV disease. Couns Psychol. 2008;36:42-89.

[8] Datti PA, Conyers LM. Application of the behavioral model of service utilization to predicting factors associated with vocational rehabilitation use among a sample of Latino men with HIV/AIDS in New York State. J Vocat Rehabil. 2010;33:15-25.

[9] Jung Y, Bellini JL. Predictors of employment outcomes for vocational rehabilitation consumers with HIV/AIDS: 2002-2007. Rehabil Couns Bull. 2011;54:142-153.

[10] Rousseau AS, Conyers LM, Armstrong A. Rehabilitation service utilization among African American women living with HIV/AIDS: Applying the behavioral model for vulnerable populations. Rehabil Couns Bull. Prepublished August 25, 2015. doi: 10.1177/0034355215601354.

[11] Gomez W, Flentje A, Schustack A, et al. Navigating barriers to vocational rehabilitation for HIV-positive persons. AIDS Behav. 2015; [cited 2016 Jan 29]. Available from: http://link. springer.com/article/10.1007\%2Fs10461-015-1261-1.

[12] Martin DJ, Arns PG, Batterham PJ, et al. Workforce reentry for people with HIV/AIDS: intervention effects and predictors of success. Work. 2006;27:221-233.

[13] Conyers LM, Boomer KB. Examining the role of vocational rehabilitation on access to care and public health outcomes for people living with HIV/AIDS. Disabil Rehabil. 2014;36:1203-1210.

[14] Nachega JB, Uthman OA, Peltzer K, et al. Association between antiretroviral therapy adherence and employment status: systematic review and meta-analysis. Bull World Health Organ. 2015;93:29-41.

[15] Kohlenberg B, Watts MW. Considering work for people living with HIV/AIDS: Evaluation of a group employment counseling program [Internet]. [cited 2015 Apr 13]. Available from: Available from: http://www.bkohlenberg.com/pdfs/3n_ Jo_of_Rehab_MAP_grp.pdf.

[16] Liukkonen V, Virtanen P, Vahtera J, et al. Employment trajectories and changes in sense of coherence. Eur J Public Health. 2009;20:293-298.

[17] Virtanen P, Vahtera J, Broms U, et al. Employment trajectory as determinant of change in health-related lifestyle: the prospective HeSSup study. Eur J Public Health. 2008;18:504-508.

[18] Richardson LA, DeBeck K, Wood E, Montaner JSG, Kerr T. Employment loss and changes in exposure to factors associated with HIV infection among people who inject drugs in Vancouver, Canada. 22nd Annual Canadian Conference on HIV Research 2013 Apr; Vancouver, Canada.

[19] Richardson LA, Milloy MJS, Kerr T, et al. Employment predicts decreased mortality among HIV-seropositive illicit drug users in a setting of universal HIV care. J Epidemiol Community Health. 2014;68:93-96.
[20] Goldblum P, Kohlenberg B. Vocational counseling for people with HIV: the client-focused considering work model. J Vocat Rehabil. 2005;22:115-124.

[21] Prochaska JO, Norcross JC, Diclemente PCC. Changing for good: the revolutionary program that explains the six stages of change and teaches you how to free yourself. New York: William Morrow; 1994. p. 304.

[22] Conyers LM. Expanding understanding of HIV/AIDS and employment: perspectives of focus groups. Rehabil Couns Bull. 2004;48:5-18.

[23] Conyers LM. Overview of the National Working Positive Coalition Employment Needs Survey. US Department of Labor HIV/AIDS Employment Roundtable; 2011 Apr 8; HIV/ AIDS Employment Roundtable Summary of Proceedings: United States Department of Labor.

[24] Wu AW. MOS-HIV health survey users manual. Baltimore, MD: John Hopkins University; 1999.

[25] Muthén LK, Muthén BO. Mplus users guide. 7th ed. Los Angeles, CA: Muthén \& Muthén; 1998-2012.

[26] Muthén BO, Du Toit SHC, Spisic D. 1997. Robust inference using weighted least squares and quadratic estimating equations in latent variable modeling with categorical and continuous outcomes. Unpublished technical report; [cited 2015 Apr 10]. Available from: http://www.statmodel.com/ download/Article_075.pdf.

[27] Brown TA. Confirmatory factor analysis for applied research. New York, NY: Guilford Press; 2006. 475 p.

[28] Zhao X, Lynch JG, Chen Q. Reconsidering Baron and Kenny: myths and truths about mediation analysis. J Cons Res. 2010;37:197-206.

[29] Lent RW, Brown SD, Hackett G. Toward a unifying social cognitive theory of career and academic interest, choice, and performance. J Vocat Behav. 1994;45:79-122.

[30] Conyers LM, Boomer KB. Factors associated with disclosure of HIV/AIDS to employers among individuals who use job accommodations and those who do not. J Vocat Rehabil. 2005;22:189-198.

[31] Bandura A. Self-efficacy: toward a unifying theory of behavioral change. Psychol Rev. 1977;84:191-215.

[32] Laudet AB, Magura S, Vogel HS, et al. Interest in and obstacles to pursuing work among unemployed dually diagnosed individuals. Subst Use Misuse. 2002;37:145-170.

[33] Conyers LM. HIV/AIDS as an emergent disability: the response of vocational rehabilitation. J Vocat Rehabil. 2005;22:67-73.

[34] Chesney MA, Smith AW. Critical delays in HIV testing and care: the potential role of stigma. Am Behav Sci. 1999;42:1162-1174.

[35] Marmot M, Friel S, Bell R, et al. Closing the gap in a generation: health equity through action on the social determinants of health. The Lancet. 2008;372:1661-1669.

[36] Rueda S, Raboud J, Plankey $M$, et al. Labor force participation and health-related quality of life in HIV-positive men who have sex with men: the multicenter AIDS cohort study. AIDS Behav. 2012 Nov 1;16:2350-2360.

[37] Conyers LM. The impact of vocational services and employment on people with HIV/AIDS. Work. 2004 Nov;23:205-214.

[38] Rueda S, Raboud J, Mustard C, et al. Employment status is associated with both physical and mental health quality of life in people living with HIV. AIDS Care. 2011;23:435-443.

[39] Bernell SL, Shinogle JA. The relationship between HAART use and employment for HIV-positive individuals: an empirical analysis and policy outlook. Health Policy. 2005 Feb;71:255-264. 
[40] Fogarty A, Zablotska I, Rawstorne P, et al. Factors distinguishing employed from unemployed people in the positive health study. AIDS. 2007;21:S37-S42.

[41] Blalock AC, McDaniel JS, Farber EW. Effect of employment on quality of life and psychological functioning in patients with HIV/AIDS. Psychosomatics. 2002;43:4003.

[42] Swindells S, Mohr J, Justis JC, et al. Quality of life in patients with human immunodeficiency virus infection: impact of social support, coping style and hopelessness. Int J STD AIDS. 1999;10:383-391.

[43] Conyers LM. HIV/AIDS and employment research: a need for an integrative approach. Couns Psychol. 2008;36: 108-117.
[44] Gardner EM, McLees MP, Steiner JF, et al. The spectrum of engagement in HIV care and its relevance to test-and-treat strategies for prevention of HIV infection. Clin Infect Dis. 2011;52:793-800.

[45] White House Office of National AIDS Policy. National HIV/ AIDS strategy for the United States: Updated to 2020. 2015. Washington, DC: The White House; [cited 2015 Oct 21]. Available from: https://www.aids.gov/federal-resources/ national-hiv-aids-strategy/nhas-update.pdf.

[46] International Labour Office. 2010. Recommendation concerning HIV and AIDS and the world of work. International Labour Organization; [cited 2016 Jan 25]. Available from: http://www.ilo.org/aids/WCMS_142706/lang-en/index.htm. 